\title{
Delayed neuropsychological sequelae after carbon monoxide poisoning: predictive risk factors in the Emergency Department. A retrospective study
}

Giuseppe Pepe ${ }^{1 \dagger}$, Matteo Castelli $i^{{ }^{*} \dagger}$, Peiman Nazerian ${ }^{1 \dagger}$, Simone Vanni ${ }^{1 \dagger}$, Massimo Del Panta ${ }^{1 \dagger}$, Francesco Gambassi ${ }^{2 \dagger}$, Primo Botti ${ }^{2+}$, Andrea Missanelli ${ }^{2+}$, Stefano Grifoni ${ }^{1+}$

\begin{abstract}
Background: Delayed neuropsychological sequelae (DNS) commonly occur after recovery from acute carbon monoxide (CO) poisoning. The preventive role and the indications for hyperbaric oxygen therapy in the acute setting are still controversial. Early identification of patients at risk in the Emergency Department might permit an improvement in quality of care. We conducted a retrospective study to identify predictive risk factors for DNS development in the Emergency Department.

Methods: We retrospectively considered all CO-poisoned patients admitted to the Emergency Department of Careggi University General Hospital (Florence, Italy) from 1992 to 2007. Patients were invited to participate in three follow-up visits at one, six and twelve months from hospital discharge. Clinical and biohumoral data were collected; univariate and multivariate analysis were performed to identify predictive risk factors for DNS.

Results: Three hundred forty seven patients were admitted to the Emergency Department for acute CO poisoning from 1992 to 2007; 141/347 patients participated in the follow-up visit at one month from hospital discharge. Thirty four/141 patients were diagnosed with DNS (24.1\%). Five/34 patients previously diagnosed as having DNS presented to the follow-up visit at six months, reporting a complete recovery. The following variables (collected before or upon Emergency Department admission) were associated to DNS development at one month from hospital discharge in the univariate analysis: CO exposure duration $>6$ hours, a Glasgow Coma Scale (GCS) score $<9$, seizures, systolic blood pressure $<90 \mathrm{mmHg}$, elevated creatine phosphokinase concentration and leukocytosis. There was no significant correlation with age, sex, voluntary exposure, headache, transient loss of consciousness, GCS between 14 and 9, arterial lactate and carboxyhemoglobin concentration. The multivariate analysis confirmed as independent prognostic factors GCS <9 (OR 7.15; Cl 95\%: 1.04-48.8) and leukocytosis (OR 3.31; Cl 95\%: 1.0210.71).
\end{abstract}

Conclusions: Our study identified several potential predictive risk factors for DNS. Treatment algorithms based on an appropriate risk-stratification of patients in the Emergency Department might reduce DNS incidence; however, more studies are needed. Adequate follow-up after hospital discharge, aimed at correct recognition of DNS, is also important.

\footnotetext{
* Correspondence: matte.castelli@inwind.it

+ Contributed equally

${ }^{1}$ Emergency Department, Careggi University General Hospital, Via delle

Oblate 1, 50139, Florence, Italy

Full list of author information is available at the end of the article
} 


\section{Background}

Carbon monoxide ( $\mathrm{CO})$ is a common cause of poisoning, resulting in more than 40.000 cases per year in the United States [1,2]. In Italy, estimated incidence is about 6.000 cases per year (resulting in more than 350 deaths/ year) [3]; in the United Kingdom, about 50 people annually die because of $\mathrm{CO}$-poisoning [4]. The real incidence is underestimated because the majority of cases go unrecognized or unreported. Presenting symptoms are notoriously aspecific (headache, asthenia, nausea, vomiting, transient loss of consciousness, altered mental status, coma) and correct diagnosis is a challenge for the emergency physician. Mortality among patients admitted to the hospital is low, and prevention of delayed neuropsychological sequelae (DNS) has become the main goal of treatment. DNS usually develop within some weeks after an initial complete clinical recovery from acute poisoning. The reported incidence varies widely from 3 to $40 \%$, because of the lack of established diagnostic criteria [1-16]. Most frequently described sequelae include a broad spectrum of neurological deficits, cognitive impairments and affective disorders [Table 1] [1-16]. DNS gradually resolve over the the first months but can be permanent in about $25 \%$ of cases [1-16]; patients with persistent complaints are usually referred to a specialist for long-term therapy. Patient's initial presentation does not predict the development of DNS with certainty, but some variables have been associated to DNS: older age, duration of exposure to $\mathrm{CO}$, longer time to treatment, transient loss of

\section{Table 1 Signs and symptoms of delayed neuropsychological sequelae}

\begin{tabular}{ll}
\hline Neurological sequelae & Cognitive and psychological sequelae \\
\hline Parkinson-like syndromes & Concentration deficit \\
Gait and motor disturbances & Memory loss \\
Bradykinesia & Cognitive impairment \\
Intention tremor & Dementia \\
Myoclonus & Personality changes \\
Dyspraxia & Anxiety \\
Dysphasia & Extreme emotional lability \\
Ataxia & Psychosis \\
Postural instability & Depression \\
Vertigo & Mania \\
Cortical blindness & Insomnia \\
Hearing loss, tinnitus & \\
Chorea & \\
EEG abnormalities & \\
Epilepsy & \\
Peripheral neuropathies & \\
Fecurrent headache & \\
\hline Fecal/urinay incontinence & \\
\hline
\end{tabular}

References: [1-18]. consciousness, coma, abnormal results on early neuropsychometric testing, severe metabolic acidosis, high arterial lactate level, increased serum levels of neuronspecific enolase (NSE), increased levels of myelin basic protein in the cerebrospinal fluid and early head computed tomography $(\mathrm{CT})$ or magnetic resonance (MRI) abnormalities [1,2,5-18]. The preventive role of hyperbaric oxygen $(\mathrm{HBO})$, administered in the acute setting, has been evaluated in several trials [6-13] and one metanalysis [14] but results are controversial. In particular there are uncertainties about early identification of patients for whom $\mathrm{HBO}$ is most likely to benefit $[1,2,15,16]$. Treatment algorithms are variable but it is currently recommended to consider $\mathrm{HBO}$ administration to patients presenting at least one of these signs or symptoms before or upon hospital admission: coma, seizures, transient loss of consciousness, altered mental status, abnormal neurological signs, myocardial injury and severe metabolic acidosis. It is also considered a therapeutic option for pregnant women and young children $[1,2,15,16]$. An elevated carboxyhemoglobin level (>25\%; $>15 \%$ during pregnancy) is still considered an appropriate indication in some treatment algorithms [2]; however, this value does not reflect poisoning severity and even high values have not been associated to DNS $[1,15,16]$. A correct identification of the patients at risk in the Emergency Department (ED) might be useful in order to improve treatment, prevent DNS and allow an appropriate medical follow-up after hospital discharge. We conducted a retrospective study to identify which early clinical and instrumental data, available to the emergency physician, predict the development of DNS.

\section{Methods}

A retrospective medical record review was conducted on all CO-poisoned patients admitted to the ED of Careggi University General Hospital from 1992 to 2007. Carboxyhemoglobin levels were measured by an arterial blood gas analyzer with a CO-oximeter. A carboxyhemoglobin level at admission greater than $5 \%$ in non-smokers and $>10 \%$ in smokers was considered diagnostic [1,2]; patients with a lower level but with suggestive symptoms and a confirmed exposure to $\mathrm{CO}$ (through the use of ambient $\mathrm{CO}$ detectors by emergency medical services or the presence of relatives or cohabitants with diagnosed poisoning) were also included. Patients with mixed poisoning (carbon monoxide and drugs, alcohol or cyanide) were excluded. Every patient received highflow supplemental oxygen in the acute setting. In our hospital CO-poisoned patients are currently treated with $\mathrm{HBO}$ according to specific criteria [3] (pregnant women, children $<2$ years old, presence of GCS <9, seizures, transient loss of consciousness, altered mental status, abnormal neurological signs, evidence of myocardial 
injury and severe metabolic acidosis - $\mathrm{pH}<7.2$ ), but an hyperbaric chamber became available only in 2001. Consequently, every patient admitted before 2001, despite poisoning severity, was treated with normobaric oxygen (NBO), defined as supplemental oxygen administration in the highest concentrations available. The presence of the following variables collected before or upon ED admission was considered: age, sex, duration of $\mathrm{CO}$ exposure ( $>$ or $<6$ hours), voluntary or accidental exposure, coma (defined as Glasgow Coma Scale (GCS) <9), transient loss of consciousness, seizures, altered level of consciousness (defined as GCS between 9 and 14), headache, postural instability (defined as positive Romberg's sign), systolic blood pressure $<90 \mathrm{mmHg}$, evidence of myocardial injury (defined as electrocardiographic signs of ischaemia/arrythmias and/or cardiac enzymes elevation), dyspnea, carboxyhemoglobin level, pH, paCO2, paO2 and lactate levels in an arterial blood sample at admission. Haemoglobin ( $\mathrm{Hb}$ ), platelet count (Plt), white blood cell count (WBC), troponin I and creatine phosphokinase $(\mathrm{CPK})$ concentration in a venous blood sample obtained within 6 hours from admission were also collected; treatment modality ( $\mathrm{HBO}$ or $\mathrm{NBO}$ ) was also considered. Every patient was invited to participate in three follow-up visits in a dedicated outpatient clinic at one, six and twelve months from hospital discharge. During the visit a complete neurological exam was performed and Folstein Mini Mental Status Examination (MMSE) was administered. DNS were defined as the presence of neurological, cognitive or affective disorders [Table 1], developed after hospital discharge. Neuroradiological imaging (head CT/head MRI or SPECT) was proposed to patients suffering from DNS.

\section{Statistical analysis}

We investigated the prognostic value of the analyzed variables for the occurrence of DNS development at one month from hospital discharge. We performed univariate analysis in which the variables were compared between patients with DNS and patients with a complete clinical recovery. We used Student's t-test and analysis of variance for continuous variables and Fisher's test for categorical variables. HBO therapy was considered a categorical variable (yes/not). Univariate analysis was performed using a logistic regression model to estimate the odds ratio (OR) of developing DNS, along with 95\% confidence interval (CI). Variables significantly related to DNS development were selected, multivariate analysis was performed (stepwise forward regression model) and OR estimated. Then a comparison was performed (using Student's t-test and analysis of variance for continuous variables and Fisher's test for categorical variables) between the group of patients treated with $\mathrm{HBO}$ and the group treated with NBO. The potential benefit of $\mathrm{HBO}$ (in terms of DNS incidence reduction at one month) was investigated. Only patients presenting signs or symptoms currently considered indications for $\mathrm{HBO}$ in our hospital were included; patients treated with NBO because of the absence at admission of signs and symptoms considered indications for $\mathrm{HBO}$ were excluded. For all tests, two-sided p-values less than .05 were considered statistically significant. In text and tables, variables are expressed as mean \pm standard deviation (SD). Statistical analysis have been conducted using the SPSS statistical package software, v. 14.0, SPSS, Chicago, Illinois).

\section{Results}

Three hundred fifty seven CO-poisoned patients presented to the ED from 1992 to 2007 (mean age: $41 \pm 21$ years; males: 160). Ten patients were excluded because of mixed poisoning with drugs (mainly benzodiazepines and antidepressants) or alcohol. More than 65\% of patients were transported to the ED by emergency medical services. Presenting clinical characteristics were aspecific; the signs and symptoms most commonly reported are listed in Table 2. Evidence of myocardial injury was present in $17.2 \%$ of patients; systolic blood pressure $<90 \mathrm{mmHg}$ in $1.7 \%$. Severe metabolic acidosis (arterial $\mathrm{pH}<7.2$ ), dyspnea or cardiac chest pain (defined as the presence of chest pain associated to electrocardiographic signs of ischaemia/arrythmias and/or cardiac enzymes elevation) were present in less than $6.5 \%$ of patients. The cherry pink colour of the skin, traditionally considered distinctive of $\mathrm{CO}$ poisoning, was

Table 2 Presenting signs and symptoms of acute carbon monoxide poisoning

\begin{tabular}{lll}
\hline Signs/symptoms in the Emergency Department & $\mathbf{n}=\mathbf{3 4 7}$ & $\mathbf{\%}$ \\
\hline Headache & 203 & $58.5 \%$ \\
\hline Transient loss of consciousness & 142 & $40.9 \%$ \\
\hline Sinus tachycardia & 90 & $25.9 \%$ \\
\hline Nausea/vomiting & 87 & $25.0 \%$ \\
\hline Asthenia & 70 & $20.1 \%$ \\
\hline Dizziness & 70 & $20.1 \%$ \\
\hline Palpitations & 64 & $18.4 \%$ \\
\hline Evidence of myocardial injury & 60 & $17.2 \%$ \\
\hline GCS between 14 and 9 & 53 & $15.2 \%$ \\
\hline Postural instability & 37 & $10.6 \%$ \\
\hline GCS $<9$ & 29 & $8.3 \%$ \\
\hline Seizures & 24 & $6.9 \%$ \\
\hline Dyspnea & 22 & $6.3 \%$ \\
\hline Severe metabolic acidosis $(\mathrm{pH}<7.2)$ & 15 & $4.3 \%$ \\
\hline Cardiac chest pain & 6 & $1.7 \%$ \\
\hline Systolic blood pressure $<90 \mathrm{mmHg}$ & 6 & $1.7 \%$ \\
\hline 347 patiens,
\end{tabular}

347 patients. 
present in less than $1 \%$ of patients. Sixteen patients (4.6\%) were asymptomatic but with diagnostic carboxyhemoglobin levels. Mean carboxyhemoglobin level at admission was $24.8 \pm 10 \%$; this value did not correlate with poisoning clinical severity. Two elderly patients died in the ED (0.57\%), both presenting coma, myocardial injury and haemodynamic instability. Mean duration of hospitalization was $3.7 \pm 2.5$ days. Ninety-six/347 (27.6\%) patients were treated with $\mathrm{HBO}$, in 3 cases because of pregnancy and in 3 cases because of age $<2$ years. The remainder patients $(251 / 347,72.4 \%)$ were treated with NBO; patients admitted before 2001 received NBO despite the presence of signs and symptoms currently considered indications for $\mathrm{HBO}$. One hundred forty one/347 (40.6\%) patients were evaluated at 30 days from discharge (mean age: $42 \pm 21$ years; males: 64); DNS were diagnosed in 34/141 (24.1\%). The remainder patients completely recovered and resumed their former occupation after hospital discharge. Only 13/141 patients (9.2\%) participated to the follow-up visit at six months from hospital discharge. Five were previously diagnosed as having DNS and reported a complete recovery. None of the patients presented to the visit at one year. Most frequent sequelae consisted of mild cognitive dysfunctions: memory and concentration impairment (25/34), difficulty in calculating (9), writing and reading (5). Mean MMSE score was $24.1 \pm 1.7$. Fifteen patients developed recurrent headache. Five patients complained of affective disorders (depression or anxiety) diagnosed by a specialist after hospital discharge; three patients suffered from insomnia. Abnormal neurological signs were rare $(7 / 34)$, mainly related to cerebellar and basal ganglia injury: postural instability, rigidity, bradykinesia, gait disturbances, intention tremor, impaired coordination and dysarthria. Dyspraxia, dysphasia and anosmia developed respectively in three, two and one patient. A Parkinson-like syndrome with severe cognitive impairment and urinary incontinence developed in another case (a 66 years-old male presenting coma and haemodynamic instability at admission). The univariate analysis identified the variables associated to DNS development: $\mathrm{CO}$ exposure duration $>6$ hours $(\mathrm{p}=0.03), \mathrm{GCS}<9$ at admission $(\mathrm{p}=0.002)$, seizures $(\mathrm{p}$ $=0.001)$ and systolic blood pressure $<90 \mathrm{mmHg}(\mathrm{p}=$ 0.04 ). A CPK concentration $>160 \mathrm{U} / \mathrm{L}$ (normal range: 20-160 U/L) and leukocytosis (WBC >10.000/microliter) within 6 hours from admission also resulted associated $(\mathrm{p}=0.01$ and $\mathrm{p}=0.004)$. There was no correlation with age, sex, suicide attempt, duration of exposure, transient loss of consciousness, GCS between 14 and 9, metabolic acidosis and blood gas analysis abnormalities, in particular carboxyhemoglobin level at admission. HBO administration (55/141 patients, 39\%) did not result associated to a significant reduction in the DNS incidence at one month $(\mathrm{p}=0.36)$ [Table 3]. The multivariate analysis confirmed as independent variables predictive of risk GCS <9 (OR 7.15; CI 95\%: 1.04-48.8) and leukocytosis within 6 hours from admission (OR 3.31; CI 95\%: 1.0210.71) [Table 4]. The inclusion of categorical variable "HBO therapy" in the previous multivariate analysis confirmed the lack of an association between DNS and $\mathrm{HBO}$, confirming at the same time the correlation with leukocytosis and GCS $<9$. Among the 141 patients who presented to the first follow-up visit, 108 presented at admission signs or symptoms currently considered indications for $\mathrm{HBO}$ in our hospital. Patients admitted before 2001 were treated with NBO, because of the unavailability of an hyperbaric chamber in our hospital (53/ $108,49 \%)$. The remainder patients $(55 / 108,50.9 \%)$ were treated with HBO. The base-line characteristics of the two groups are reported in Table 5. The DNS incidence at one month was $26.8 \%$ (29/108 patients), the difference between the two groups was not statistically significant $23.6 \%$ in the $\mathrm{HBO}$ group vs. $30.1 \%$ in the NBO group; $\mathrm{p}=0.44)$. The univariate analysis did not show a significant association between $\mathrm{HBO}$ administration and DNS incidence reduction (OR 0.72; IC 95\%: 0.30-1.68). Among patients who suffered from DNS, 5(14.7\%) did not present at admission signs or symptoms currently considered indications for $\mathrm{HBO}$.

\section{Discussion}

In our study, DNS resulted a relatively frequent complication of $\mathrm{CO}$ poisoning (24.1\% incidence at 30 days from hospital discharge) although clinically mild in most cases. Mortality among $\mathrm{CO}$ poisoned patients admitted to the hospital was low $(0.57 \%)$. We identified several clinical and instrumental data associated to DNS development. Prolonged CO exposure, seizures and GCS $<9$ are expression of severe poisoning with high probability of neurological injury. A systolic blood pressure $<90 \mathrm{mmHg}$, although significantly correlated with DNS development, was present in only four patients, a number too low to draw definitive conclusions. Increased CPK concentration ( $>160 \mathrm{U} / \mathrm{L})$ indicates both CO-mediated muscle necrosis and rhabdomyolysis in comatose patients lying on the floor for a long time. Leukocytosis is a condition that has never been associated to DNS, but this result can be interpreted considering the role of activated leukocytes in the pathogenesis of neurological injury, mainly attributable to oxidative stress and inflammation, than to hypoxia $[19,20]$. However, considering the limited difference in white blood cell count between the two groups of patients (non-DNS and DNS), our finding does not seem to have a clinically relevant impact. Furthermore, whether antiinflammatory therapy could prevent DNS is unknown $[1,16]$. On the other hand, we did not find an association between DNS and some variables previously 
Table 3 Base-line characteristics of patients and association between variables and DNS development

\begin{tabular}{|c|c|c|c|c|}
\hline $\begin{array}{l}\text { Variables (before or } \\
\text { upon ED admission) }\end{array}$ & $\begin{array}{l}\text { Patient number }= \\
141 \text { mean } \pm \text { SD }\end{array}$ & $\begin{array}{l}\text { Non-DNS group at one month from } \\
\text { hospital discharge (patient } n=107 \text { ) } \\
\text { mean } \pm \text { SD }\end{array}$ & $\begin{array}{l}\text { DNS group at one month from hospital } \\
\text { discharge (patient } n=34 \text { ) mean } \pm S D\end{array}$ & $p$ value \\
\hline Age (years) & $42 \pm 21$ & $41.7 \pm 21.7$ & $40.4 \pm 15.5$ & $>.05$ \\
\hline Sex (male) & $64(45.3 \%)$ & $53(49.5 \%)$ & $11(32.3 \%)$ & $>.05$ \\
\hline $\begin{array}{l}\text { Duration of exposure }>6 \\
\text { hours }\end{array}$ & $54(38.2 \%)$ & $36(33.6 \%)$ & $18(52.9 \%)$ & .03 \\
\hline Suicide attempt & $5(3.5 \%)$ & $3(2.8 \%)$ & $2(5.8 \%)$ & $>.05$ \\
\hline $\mathrm{Hb}(\mathrm{g} / \mathrm{dL})$ & $14 \pm 1.6$ & $14.1 \pm 1.16$ & $13.7 \pm 1.9$ & $>.05$ \\
\hline WBC (per microlitre) & $9.87 \pm 3.7$ & $9.100 \pm 2.900$ & $11.900 \pm 4.900$ & .004 \\
\hline Plt (per microlitre) & $234.300 \pm 58.300$ & $236.000 \pm 61.700$ & $228.000 \pm 47.000$ & $>.05$ \\
\hline $\begin{array}{l}\text { Troponin I (ng/mL) }(n= \\
\text { 43) }\end{array}$ & $0.72 \pm 3.25$ & $0.88 \pm 3.88(n=30)$ & $0.33 \pm 0.66(n=13)$ & $>.05$ \\
\hline CPK $(U / L)(n=127)$ & $255 \pm 763$ & $159 \pm 221(n=97)$ & $572 \pm 1506(n=30)$ & .01 \\
\hline Lactate $(\mathrm{mmol} / \mathrm{L})(\mathrm{n}=82)$ & $1.77 \pm 1.46$ & $1.77 \pm 1.41(n=62)$ & $1.76 \pm 1.34(n=20)$ & $>.05$ \\
\hline $\mathrm{pH}$ & $7.41 \pm 0.07$ & $7.40 \pm 0.07$ & $7.41 \pm 0.07$ & $>.05$ \\
\hline $\mathrm{paCO} 2(\mathrm{KPa})$ & $4.78 \pm 0.87$ & $4.82 \pm 0.89$ & $4.62 \pm 0.74$ & $>.05$ \\
\hline $\mathrm{paO} 2(\mathrm{KPa})$ & $15.33 \pm 1.09$ & $14.93 \pm 7.34$ & $16.53 \pm 10.45$ & $>.05$ \\
\hline GCS $<9$ & $15(10.6 \%)$ & $6(5.6 \%)$ & $9(26.4 \%)$ & .002 \\
\hline $\begin{array}{l}\text { Transient loss of } \\
\text { consciousness }\end{array}$ & 75 (53.1\%) & $53(49.5 \%)$ & $22(64.7 \%)$ & $>.05$ \\
\hline Seizures & $14(9.9 \%)$ & $5(4.6 \%)$ & $9(26.4 \%)$ & .001 \\
\hline $\begin{array}{l}\text { Systolic blood pressure } \\
<90 \mathrm{mmHg}\end{array}$ & $4(2.8 \%)$ & $1(0.9 \%)$ & $3(8.8 \%)$ & .04 \\
\hline Postural instability & 37 (26.2\%) & $26(24.2 \%)$ & $11(32.3 \%)$ & $>.05$ \\
\hline Headache & 79 (56\%) & $60(56 \%)$ & 19 (55.8\%) & $>.05$ \\
\hline GCS between 14 and 9 & $29(20.5 \%)$ & $26(24.2 \%)$ & $3(8.8 \%)$ & $>.05$ \\
\hline $\begin{array}{l}\text { Severe metabolic acidosis } \\
(\mathrm{pH}<7.2)\end{array}$ & $11(7.8 \%)$ & $6(5.6 \%)$ & $5(14.7 \%)$ & $>.05$ \\
\hline Dyspnea & $6(4.2 \%)$ & $4(3.7 \%)$ & $2(5.8 \%)$ & $>.05$ \\
\hline $\begin{array}{l}\text { Mean } \\
\text { carboxyhemoglobin level } \\
\text { at admission (\%) }\end{array}$ & $26.3 \pm 10$ & $26 \pm 10.2$ & $26.4 \pm 10.5$ & $>.05$ \\
\hline $\begin{array}{l}\text { Evidence of myocardial } \\
\text { injury }\end{array}$ & 33 (23.4\%) & $23(21,4 \%)$ & $10(29,4 \%)$ & $>.05$ \\
\hline HBO therapy & 55 (39\%) & $44(41.1 \%)$ & $11(32.3 \%)$ & $>.05$ \\
\hline
\end{tabular}

$141 / 347(40,6 \%)$ patients participated in the follow-up visit at one month from hospital discharge.

Table 4 Predictive risk factors for DNS development

\begin{tabular}{lll}
\hline Variables & $\begin{array}{l}\text { Univariate analysis Odds ratio (confidence interval: } \\
\mathbf{9 5 \%}\end{array}$ & $\begin{array}{l}\text { Multivariate analysis Odds ratio (confidence } \\
\text { interval: 95\%) }\end{array}$ \\
\hline $\begin{array}{l}\text { Systolic blood pressure }<90 \\
\mathrm{mmHg}\end{array}$ & $10.25(1.40-73.68)$ & $1.34(0.04-40.85)$ \\
\hline Seizures & $7.34(2.53-22.28)$ & $1.65(0.18-14.85)$ \\
\hline $\mathrm{GCS}<9$ & $6.06(2.04-17,95)$ & $7.15(1.04-48.8)$ \\
\hline $\begin{array}{l}\text { Leukocytosis }(\mathrm{WBC}>10.000 / \\
\text { microlitre) }\end{array}$ & $3.13(1.31-7.95)$ & $3.31(1.02-10.71)$ \\
\hline Duration of exposure $>6$ hours & $2.13(0.87-5.24)$ & $1.28(0.09-2.9)$ \\
\hline CPK $>160 \mathrm{U} / \mathrm{L}$ & $1.14(0.49-2.60)$ & $1.02(0.4-1.64)$ \\
\hline
\end{tabular}

Odds ratios for the association of variables with DNS development at one month from hospital discharge. Univariate and multivariate analysis. 
Table 5 Comparison between DNS incidence among patients treated with NBO and patients treated with HBO. Baseline characteristics of patients $(n=108)$

\begin{tabular}{|c|c|c|c|c|}
\hline $\begin{array}{l}\text { Variables (before or upon ED } \\
\text { admission) }\end{array}$ & $\begin{array}{l}\text { Patient number }=108 \\
\text { mean } \pm \text { SD }\end{array}$ & $\begin{array}{l}\text { OTI group (patient } n=55 \text { ) } \\
\text { mean } \pm S D\end{array}$ & $\begin{array}{l}\text { OTN group (patient } n=53 \text { ) } \\
\text { mean } \pm S D\end{array}$ & $p$ value \\
\hline Age (years) & $44 \pm 20$ & $40.6 \pm 20.4$ & $48.2 \pm 21.5$ & $>.05$ \\
\hline Sex (male) & $50(50.9 \%)$ & $23(41.8 \%)$ & $27(50.9 \%)$ & $>.05$ \\
\hline Duration of exposure $>6$ hours & $41(37.9 \%)$ & $27(49.9 \%)$ & $14(26.4 \%)$ & .01 \\
\hline Suicide attempt & $4(3.7 \%)$ & $3(5.4 \%)$ & $1(1.8 \%)$ & $>.05$ \\
\hline $\mathrm{Hb}(\mathrm{g} / \mathrm{dL})$ & $14 \pm 1.7$ & $13.8 \pm 1.6$ & $14 \pm 1.8$ & $>.05$ \\
\hline WBC (per microlitre) & $10.100 \pm 3.890$ & $10.300 \pm 4.100$ & $9.800 \pm 3.500$ & $>.05$ \\
\hline Plt (per microlitre) & $226.000 \pm 50.000$ & $220.100 \pm 45.000$ & $233.000 \pm 54.300$ & $>.05$ \\
\hline Troponin I (ng/mL) $(n=36)$ & $0.85 \pm 3.54$ & $0.98 \pm 3.88(n=30)$ & $0.22 \pm 0.44(n=6)$ & $>.05$ \\
\hline CPK $(U / L)(n=93)$ & $298 \pm 867$ & $385 \pm 1149(n=50)$ & $195 \pm 265(n=43)$ & $>.05$ \\
\hline Lactate $(\mathrm{mmol} / \mathrm{L})(\mathrm{n}=65)$ & $1.94 \pm 1.6$ & $2.05 \pm 1.78(n=43)$ & $1.75 \pm 1.1(n=22)$ & $>.05$ \\
\hline $\mathrm{pH}$ & $7.40 \pm 0.08$ & $7.41 \pm 0.06$ & $7.39 \pm 0.1$ & $>.05$ \\
\hline $\mathrm{paCO} 2(\mathrm{KPa})$ & $4.81 \pm 0.94$ & $4.73 \pm 0.6$ & $4.89 \pm 1.21$ & $>.05$ \\
\hline $\mathrm{paO2}(\mathrm{KPa})$ & $15.8 \pm 8.78$ & $16.7 \pm 8.0$ & $14.7 \pm 9.4$ & $>.05$ \\
\hline GCS $<9$ & $15(13.8 \%)$ & $9(16.3 \%)$ & $6(11.3 \%)$ & $>.05$ \\
\hline Transient loss of consciousness & $75(69.4 \%)$ & $42(76.3 \%)$ & $33(62.2 \%)$ & $>.05$ \\
\hline Seizures & $14(12.9 \%)$ & $12(21.8 \%)$ & $2(3.7 \%)$ & .008 \\
\hline Systolic blood pressure $<90 \mathrm{mmHg}$ & $4(3.7 \%)$ & $1(1.8 \%)$ & $3(5.6 \%)$ & $>.05$ \\
\hline Postural instability & $32(29.6 \%)$ & $14(25.4 \%)$ & $18(33.9 \%)$ & $>.05$ \\
\hline Headache & $54(50 \%)$ & $31(63.6 \%)$ & $23(43.3 \%)$ & $>.05$ \\
\hline GCS between 14 and 9 & $29(26.8 \%)$ & $14(25.4 \%)$ & $15(28.3 \%)$ & $>.05$ \\
\hline Severe metabolic acidosis ( $\mathrm{pH}<7.2$ ) & $11(10.1 \%)$ & $5(9 \%)$ & $6(11.3 \%)$ & $>.05$ \\
\hline Dyspnea & $5(4.6 \%)$ & $2(3.6 \%)$ & $3(5.6 \%)$ & $>.05$ \\
\hline $\begin{array}{l}\text { Mean carboxyhemoglobin level at } \\
\text { admission (\%) }\end{array}$ & $27.7 \pm 9.6$ & $25.9 \pm 9.41$ & $29.5 \pm 9.7$ & $>.05$ \\
\hline Evidence of myocardial injury & $33(30.5 \%)$ & $14(25.4 \%)$ & 19 (35.8\%) & $>.05$ \\
\hline DNS incidence at one month & $29(26.8 \%)$ & $13(23.6 \%)$ & $16(30.1 \%)$ & $>.05$ \\
\hline
\end{tabular}

Only patients presenting at admission signs and symptoms currently considered indications for HBO therapy in our hospital were selected.

correlated with neurological damage in other studies [5-18]; some of them are current indications for HBO (for example, carboxyhemoglobin level, transient loss of consciousness and GCS between 9 and 14). Carboxyhemoglobin level at admission has a fundamental diagnostic role, but the lack of prognostic value was confirmed in our study. Carboxyhemoglobin level is influenced by several factors, such as pre-hospital oxygen administration and time elapsed between exposure cessation and hospital admission. At the moment, the preventive role of $\mathrm{HBO}$ has not been clearly demonstrated, and whether to use $\mathrm{HBO}$ and in which patients remains controversial. It would be useful to revise and implement the current indications for $\mathrm{HBO}$, considering the presence or the lack, in the acute setting, of reliable predictors of DNS. Furthermore, it would be interesting to evaluate the potential benefit of HBO for patients with signs and symptoms, associated to DNS development, not currently considered indications for this therapy. The lack of a statistically significant association between $\mathrm{HBO}$ administration and DNS incidence reduction was also evident in our study, although a trend in this direction was present [Table 4,5]. The fact that $5 / 34$ patients who suffered from DNS did not present, at admission, signs or symptoms currently considered indications for $\mathrm{HBO}$ could be an interesting result. However, these results were influenced by several limitations: patients treated with $\mathrm{HBO}$ presented, on average, a more severe poisoning, even excluding the 33/141 patients suffering from mild poisoning who were treated only with NBO because of the absence at admission of signs and symptoms considered indications for HBO [Table 5]; hyperbaric protocols adopted by our hyperbaric medicine specialists were not equal for all patients (mainly because of the lack of specific universally accepted guidelines) and even NBO therapy was variable (in terms of duration and oxygen concentration). Additionally, it was not possible to acquire information about prehospital treatment (in terms of supplemental oxygen and/or drugs administration). 
Our study presents some other limitations. First of all, patients' low compliance with follow up (in particular at six and twelve months) influenced the reported incidence and clinical characteristics of DNS. The reported incidence was probably overestimated, considering that compliance to follow-up (especially to the visit at one month) was probably higher in patients suffering from DNS. The even lower compliance to the next follow-up visits can be explained considering both the group of patients who completely recovered and the group of symptomatic patients who referred to a specialist; both groups interrupted the follow-up program. Additionally, this limitation did not permit us to identify late-onset DNS and to evaluate their duration. Our diagnostic accuracy was influenced by several factors. First of all, we adopted diagnostic criteria different from other studies because of the lack of established ones. Furthermore, only a few patients with DNS were evaluated with CT, MRI or single-photon emission computed tomography during follow-up. Several abnormal radiological findings associated to DNS have been reported in literature, in particular injuries of the cerebral cortex, white matter, hippocampus and globus pallidus $[1,2,16,17]$, but in our study, the majority of patients consulted a specialist and underwent neuroradiological imaging privately, interrupting the follow-up.

\section{Conclusions}

Acute $\mathrm{CO}$ poisoning is still a challenge in emergency medicine: correct diagnosis, optimal treatment and DNS prevention are fundamental goals. There are no established criteria, if any, for determining the risk for DNS. Appropriate information about DNS should be given to every patient at the moment of hospital discharge, to allow prompt recognition of sequelae. In our study, sequelae were common after recovery from acute $\mathrm{CO}$ poisoning. We identified several potential predictive risk factors for DNS development. Early risk-stratification of patients in the Emergency Department might permit an improvement in quality of care, in terms of DNS prevention. No clear evidences are available whether or not HBO therapy is beneficial in preventing DNS, and the indications for this treatment in the acute setting remain controversial. Further research is needed to better define the optimal management of $\mathrm{CO}$ poisoning.

\section{Acknowledgements}

We acknowledge the Clinical Toxicology Unit staff for general support and follow-up activity.

\section{Author details}

${ }^{1}$ Emergency Department, Careggi University General Hospital, Via delle Oblate 1, 50139, Florence, Italy. ${ }^{2}$ Clinical Toxicology Unit, Careggi University General Hospital, Via delle Oblate 1, 50139, Florence, Italy.

\section{Authors' contributions}

GP, MC, MDP, FG and AM designed the study; GP, MC, MDP, FG, PB and AM reviewed the literature; $M C, M D P$ and $A M$ collected the data; FG, PB and $A M$ performed the follow-up activity; GP, PN and SV performed the statistical analysis; GP, MC, PN, SV, MDP, PB, AM and SG wrote the manuscript. All the authors revised and approved the manuscript.

\section{Competing interests}

The authors declare that they have no competing interests.

Received: 15 December 2010 Accepted: 17 March 2011

Published: 17 March 2011

\section{References}

1. Tomaszewski C: Carbon monoxide. In Goldfrank's toxicologic emergencies. Eight edition. Edited by: Goldfrank LR, Flomenbaum NE, Lewin NA, Howland MA, Robert S, Nelson LS. New York: Mc Graw-Hill; 2006:1689-1704

2. Maloney G: Carbon monoxide. In Tintinalli's Emergency Medicine, a comprehensive study guide. Edited by: Tintinalli JE, Stapczynski JS, Ma OJ, Cline DM, Cydulka RK, Meckler GD. New York: Mc Graw Hill; 2010:1410-13.

3. Locatelli C, Casagranda I, Coern D, Dematté P, Demicheli V, Perraro F, Pesenti Compagnoni M, Porro F, Re G: Linee guida per la gestione e il trattamento del paziente con intossicazione acuta da monossido di carbonio. GIMUPS 2000, 1:163-73.

4. Walker $E_{1}$ Hay A: Carbon monoxide poisoning. BMJ 1999, 319:1082-83.

5. Choi IS: Delayed neurologic sequelae in carbon monoxide intoxication. Arch Neurol 1983, 40:433-5.

6. Weaver LK, Valentine K, Hopkins RO: Carbon monoxide poisoning: risk factors for cognitive sequelae and the role of hyperbaric oxygen. Am J Respir Crit Care Med 2007, 176:491-7.

7. Raphael JC, Elkharrat D, Jars-Guincestre MC, Chastang C, Chasles V, Vercken JB, Gajdos P: Trial of normobaric and hyperbaric oxigen for acute carbon monoxide intoxication. Lancet 1989, 2:414-9.

8. Thom SR, Taber RL, Mendiguren II, Clark JM, Hardy KR, Fisher AB: Delayed neuropsychologic sequelae after carbon monoxide poisoning: prevention by treatment with hyperbaric oxygen. Ann Emerg Med 1995, 25:474-80

9. Mathieu D, Wattel F, Mathieu-Nolf M, Durak C, Tempe JP, Bouachour G, Sainty JM: Randomized prospective study comparing the effect of $\mathrm{HBO}$ vs 12 hours NBO in non-comatose CO-poisoned patients: results of preliminary analysis [abstract]. Undersea Hyperb Med 1996, 23:7-8.

10. Scheinkestel CD, Bailey M, Myles PS, Jones K, Cooper DJ, Millar IL, Tuxen DV: Hyperbaric or normobaric oxygen for acute carbon monoxide poisoning: a randomized controlled clinical trial. Med J Aust 1999, 170:203-10.

11. Weaver LK, Hopkins RO, Chan KJ, Churchill S, Elliott CG, Clemmer TP, Orme JF Jr: Hyperbaric oxygen for acute carbon monoxide poisoning. $N$ Engl J Med 2002, 347:1057-67.

12. Raphael JC, Chevret S, Driheme A, Annane D: Managing carbon monoxide poisoning with hyperbaric oxygen. Proceedings of the European Association of Poison Centers and Clinical Toxicologists (EAPCCT) Strasbourg: 2004, 49-50.

13. Annane D, Chadda K, Gajdos P, Jars-Guincestre MC, Chevret S, Raphael JC: Hyperbaric oxygen therapy for acute domestic carbon monoxide poisoning: two randomized controlled trials. Intensive Care Med 2011, 37:486-92.

14. Buckley NA, Isbister GK, Stokes B, Juurlink DN: Hyperbaric oxygen for carbon monoxide poisoning: a systematic review and critical analysis of the evidence. Toxicol Rev 2005, 24:75-92.

15. Wolf SJ, Lavonas EJ, Sloan EP, Jagoda AS: Clinical policy: critical issues in the management of adult patients presenting to the Emergency Department. Ann Emerg Med 2008, 51:138-52.

16. Weaver LK: Clinical practice: carbon monoxide poisoning. N Engl J Med 2009, 360:1217-25.

17. Gale SD, Hopkins RO, Weaver LK, Bigler ED, Booth EJ, Blatter DD: MRI, quantitative MRI, SPECT and neuropsychological findings following carbon monoxide poisoning. Brain Inj 1999, 13:229-43.

18. $\mathrm{Ku} \mathrm{HL}$, Yang KC, Lee YC, Lee MB, Chou YH: Predictors of carbon monoxide poisoning-induced delayed neuropsychological sequelae. Gen Hosp Psychiatry 2010, 32:310-4 
19. Thom SR, Bhopale VM, Fisher D, Zang J, Gimotty P: Delayed neuropathology after carbon monoxide poisoning is immune-mediated. Proc Natl Acad Sci USA 2004, 101:13660-5.

20. Thom SR, Bhopale VM, Han ST, Clark JM, Hardy KR: Intravascular neutrophil activation due to carbon monoxide poisoning. Am J Respir Crit Care Med 2006, 174:1239-48.

doi:10.1186/1757-7241-19-16

Cite this article as: Pepe et al:: Delayed neuropsychological sequelae after carbon monoxide poisoning: predictive risk factors in the

Emergency Department. A retrospective study. Scandinavian Journal of Trauma, Resuscitation and Emergency Medicine 2011 19:16.

Submit your next manuscript to BioMed Central and take full advantage of:

- Convenient online submission

- Thorough peer review

- No space constraints or color figure charges

- Immediate publication on acceptance

- Inclusion in PubMed, CAS, Scopus and Google Scholar

- Research which is freely available for redistribution

Submit your manuscript at www.biomedcentral.com/submit 